Key words: VEE virus/neurovirulence/nucleotide sequence/vaccine

\title{
Molecular Determinants of Alphavirus Neurovirulence: Nucleotide and Deduced Protein Sequence Changes during Attenuation of Venezuelan Equine Encephalitis Virus
}

\author{
By BARBARA J. B. JOHNSON,* RICHARD M. KINNEY, \\ CRYSTLE L. KOST AND DENNIS W. TRENT \\ Division of Vector-Borne Viral Diseases, Center for Infectious Diseases, Centers for Disease \\ Control, Public Health Service, U.S. Department of Health and Human Services, P.O. Box 2087, \\ Fort Collins, Colorado 80522, U.S.A.
}

(Accepted 21 May 1986)

SUMMARY

The nucleotide and deduced amino acid sequences of the structural proteins of the TC-83 vaccine strain of Venezuelan equine encephalitis (VEE) virus have been determined from a cDNA clone containing the $26 \mathrm{~S}$ mRNA coding region. A cDNA clone encoding the equivalent region of the virulent parent VEE virus [Trinidad donkey strain (TRD)] has been sequenced previously. Comparison of the sequences of the TC -83 and TRD cDNA clones revealed 13 nucleotide differences. Neither the organization of the structural proteins $\left(5^{\prime}\right.$-capsid $\left.-E_{3}-E_{2}-6 K-E_{1}-3^{\prime}\right)$ nor the length (3762 nucleotides) of the open reading frame coding for the viral polyprotein precursor was altered during attenuation. Of the 13 nucleotide differences between the cDNA clones of TC-83 and TRD, nine occurred in the dominant population of the respective genomic RNAs from plaque-purified viruses. Six of the nine mutations were clustered in the $\mathrm{E}_{2}$ surface glycoprotein gene. All five of the nucleotide changes which produced non-conservative amino acid substitutions in the encoded proteins were located in the $E_{2}$ gene. Two mutations occurred in the $E_{1}$ glycoprotein gene; one was silent and the other did not alter the chemical character of the $E_{1}$ protein. One nucleotide difference was found in the non-coding region immediately preceding the $5^{\prime}$-end of the $26 \mathrm{~S}$ mRNA. The $E_{2}$ and non-coding region mutations are candidates for the molecular determinants of VEE virus neurovirulence.

\section{INTRODUCTION}

Venezuelan equine encephalitis (VEE) virus has caused periodic catastrophic loss of equines in the Americas since about 1930, with severe economic consequences. Estimated equine deaths in the most recent epizootics spanning 1967 to 1971 exceeded 150000 . VEE virus also has had a substantial impact on human health, causing about 60000 cases during the 1960 's. Neurological symptoms were present in 4 to $14 \%$ of patients and the fatality rate approached $1 \%$ (Groot, 1972).

VEE virus is an attractive agent in which to characterize the molecular determinants of neurovirulence. It has a relatively simple RNA genome (about $12 \mathrm{~kb}$; Strauss \& Strauss, 1986), and closely related strains exist which differ markedly in their pathogenesis in man and animals. The virulent Trinidad donkey (TRD) strain of VEE virus and its avirulent vaccine derivative, TC-83 virus, were chosen for nucleotide sequencing studies aimed at understanding the basis for the ability of this alphavirus to invade and injure the brain.

The TC-83 vaccine strain of VEE virus was derived from the virulent TRD virus by serial passage of TRD in embryonic guinea-pig heart cells in culture (Berge et al., 1961). TC-83 virus is avirulent for weanling mice by both the intracerebral and intraperitoneal routes of inoculation (Berge $e t$ al., 1961) and is also avirulent for congenitally athymic (nude) mice (Le Blanc et al., 
1978). The attenuated virus produces viraemias which are 10- to 1000 -fold lower than those observed with virulent strains (Jahrling \& Scherer, 1973c; Le Blanc et al., 1978) and fails to produce the severe lesions in hamster haematopoietic and neuronal cells which are characteristic of TRD virus infection (Jahrling \& Scherer, 1973a). Although developed to protect laboratory and field personnel (McKinney et al., 1963), TC-83 vaccine subsequently proved invaluable in controlling the 1969 to 1971 epizootic of VEE in Central America (Walton et al., 1972; Eddy et al., 1972) and Texas (Calisher \& Maness, 1975; Baker et al., 1978). The vaccine induces long-lasting neutralizing antibody to epizootic subtypes IA to IC, but not to variants ID and IE or subtypes II to IV (Burke et al., 1977; Walton \& Johnson, 1972; Fillis \& Calisher, 1979).

TRD and TC-83 viruses are indistinguishable by classical serology (both are subtype IA) and differ only slightly in their $\mathrm{T}_{1}$ ribonuclease-resistant oligonucleotide fingerprints (Trent et al., 1979). Of the 70 large oligonucleotides of the genomic 42S RNA of the TRD strain, three were absent from the TC-83 42S RNA fingerprint. In addition, TC-83 has three unique oligonucleotides. The oligonucleotide differences observed in the fingerprints have been localized to the subgenomic 26S mRNA which encodes the structural proteins of the virus (Mecham \& Trent, 1982a). Mapping of tryptic peptides of the structural proteins (the capsid and the two envelope glycoproteins, $\mathrm{E}_{1}$ and $\mathrm{E}_{2}$ ) demonstrated that the resolvable differences between TRD and TC-83 viruses are in the $E_{2}$ membrane glycoprotein (Mecham \& Trent, $1982 \mathrm{~b}$ ), which is the haemagglutinin (France et al., 1979) and contains the type-specific neutralization epitope (Roehrig et al., 1982).

We report here the cloning and sequencing of cDNA encoding the structural proteins of TC83 virus. Comparison of this sequence with that of the virulent TRD strain (Kinney et al., 1986) has resulted in the identification of amino acids in the surface glycoproteins which may determine the neurovirulence of VEE virus.

\section{METHODS}

RNA purification, cloning and sequencing methods, and computer analyses. These were done as described previously (Kinney et al., 1986).

Virus and cultured cells. The TC-83 strain of VEE virus used was vaccine lot number 5-LD-1 produced by Merrell National Laboratory, Philadelphia, Pa., U.S.A. and was distributed by the Centers for Disease Control, Atlanta, Ga., U.S.A. The virus was plaque-purified in confluent monolayers of Vero cells, and seed stocks prepared as tissue culture fluids obtained by infection of BHK-21 cells at low multiplicity. Viral RNA for use in cDNA synthesis was isolated from purified TC-83 virus grown in BHK-21 cells. Attenuation of the plaque-purified virus was verified in mice and hamsters prior to molecular cloning. RNA was also prepared from the TRD strain of VEE virus, passage history GPB1 V6BHK21-1 (GPB = guinea-pig brain; V = Vero).

Synthesis and purification of deoxyoligonucleotide primers. Deoxyoligonucleotides for priming cDNA synthesis and for primer extension sequencing of genomic RNA were synthesized with an Applied Biosystems Model 380A DNA synthesizer using phosphoramidite chemistry (Beaucage $\&$ Caruthers, 1981). The oligonucleotides were purified by preparative gel electrophoresis through $16 \%$ acrylamide/bisacrylamide (19/1) in 7 M-urea and TBE buffer pH 8.3 ( $89 \mathrm{~mm}$-Tris, $89 \mathrm{~mm}$-boric acid, $2.8 \mathrm{~mm}$-disodium EDTA). The oligomers were located by their u.v. absorbance, the appropriate bands excised, and the DNAs eluted in $2 \mathrm{M}$-ammonium acetate at $37^{\circ} \mathrm{C}$. Oligonucleotides were then adsorbed to DE-52 cellulose (Whatman), washed with water, eluted with $30 \%(\mathrm{v} / \mathrm{v})$ triethylammonium bicarbonate $\mathrm{pH} 8$, and desalted in vacuo (C. Naeve, personal communication).

RNA sequencing. Genomic RNA (42S) was sequenced by reverse transcriptase-catalysed extension from synthetic DNA primers using dideoxynucleotide chain terminators (Sanger et al., 1977). The protocol was adapted from Ou et al. (1981). Deoxyoligonucleotide primer (about 20-fold molar excess) was hybridized to 42S RNA for 2 min at $95^{\circ} \mathrm{C}$ and then placed on ice. The concentrations of dGTP, dCTP and dTTP (P-L Biochemicals) were $3.7 \mu \mathrm{M}$ and the concentration of [ $\left.\alpha^{-32} \mathrm{P}\right] \mathrm{dATP}$ (New England Nuclear) was $1 \mu \mathrm{M}$ (sp. act. $800 \mathrm{Ci} / \mathrm{mmol}$ ). The ratio of deoxy- to dideoxynucleotides was $2 \cdot 3$. Reaction mixtures contained $44 \mathrm{mM}-\mathrm{Tris}-\mathrm{HCl} \mathrm{pH} 8 \cdot 1,8 \cdot 3 \mathrm{mM}-\mathrm{MgCl}_{2}, 54$ $\mathrm{mm}-\mathrm{KCl}, 8.3 \mathrm{~mm}$-dithiothreitol, 9 units RNasin (Promega Biotech) and 2.1 units avian myeloblastosis virus reverse transcriptase (Promega Biotech) in a final volume of $5 \mu \mathrm{l}$. The mixtures were incubated for $5 \mathrm{~min}$ at $20^{\circ} \mathrm{C}$ and then for $30 \mathrm{~min}$ at $37^{\circ} \mathrm{C}$. Nascent DNA chains were then chased by addition of $2 \mu$ of a solution containing $0.5 \mathrm{~mm}$ of each deoxynucleotide triphosphate and incubated at $37^{\circ} \mathrm{C}$ for $15 \mathrm{~min}$. Reactions were stopped with $6 \mu \mathrm{l}$ formamide/dye, boiled for $5 \mathrm{~min}$, and analysed on $0.4 \mathrm{~mm}$-thick sequencing gels (Sanger \& Coulson, 1978) which were dried before autoradiography under Kodak SB-5 film 
RESULTS

\section{Nucleotide sequence of cDNA encoding the $26 S$ RNA of TC-83 virus}

DNA complementary to the $26 \mathrm{~S}$ region of viral $42 \mathrm{~S}$ RNA was prepared for cloning into pUC18 by priming at the 3 '-end of the genome, as previously described (Kinney et al., 1986). Restriction fragments of the cloned cDNA, designated pTC-5, were subcloned into M13 phages mp10 and mp11. The entire sequence was determined on each strand of the pTC-5 cDNA and all the junctions between restriction fragments were confirmed by sequencing other fragments which contained these junctions in an internal position. In the region encoding the capsid, it was necessary to build a synthetic primer to obtain complete data on the second DNA strand and to verify Sau3A and TaqI restriction sites.

The nucleotide sequence of the $26 \mathrm{~S} \mathrm{mRNA}$ region of $\mathrm{TC}-83$ virus and the deduced amino acid sequence of the encoded proteins are shown in Fig. 1. The pTC-5 cDNA clone is 4008 nucleotides long and contains 161 nucleotides to the 5 'side of the beginning of the 26S RNA. The $3^{\prime}$-end of the cDNA clone is marked with a vertical arrow in the region complementary to the oligonucleotide used to prime the cDNA synthesis. The 65 nucleotides at the $3^{\prime}$-end of the genome [excluding the poly(A) tail] are not present in clone pTC-5, but were previously determined by Ou et al. (1982a). The overall organization of the 26S mRNA of TC-83 virus is identical to that of its virulent parent. Starting at the AUG initiation codon, an open reading frame extends for 3762 nucleotides until an opal termination codon (UGA) is reached, exactly as was found for TRD virus (Kinney et al., 1986).

\section{Comparison of the sequences of TC-83 and TRD viruses}

Nucleotide differences between the TC- 83 and TRD cDNAs are noted in Fig. 1. There are 13 differences between the pTC-5 clone and the pTRD-1 clone of the virulent virus (Kinney et al., 1986). Seven differences are in the $E_{2}$ glycoprotein, four in the $E_{1}$ glycoprotein, and one each in the $6 \mathrm{~K}$ protein and in the non-coding region preceding the beginning of the 26S RNA. The nucleotide sequences encoding the capsid and $E_{3}$ proteins of the two viruses are identical.

To ascertain whether the differences between the TC-83 and TRD cDNAs reflect differences in their respective genomic RNAs, direct RNA sequencing by primer extension was performed on each of the genomes. Reverse transcriptase errors could have introduced differences in the cDNA clones which did not exist in the viral RNA templates. Furthermore, RNA genomes are highly mutable, and it was possible that we cloned a minor variant from a heterogeneous population of RNA molecules. Viruses used in this study were plaque-purified at terminal dilution before they were grown for RNA isolation to minimize this possibility.

Seven deoxynucleotide primers complementary to the positive strand of the cDNAs were synthesized, purified and used to sequence genomic RNAs across the regions where the 13 differences between the cDNAs were found. The regions sequenced are shown in Fig. 2. Three cDNA differences were unconfirmed at the RNA sequence level; these are marked with an ' $X$ '. (The structure revealed by RNA sequencing is a weighted average of the mixture of mutants present in the sample.) Nucleotide number 1657 from the 5 -start of the 26S RNA was found to be a $\mathrm{G}$ in both viruses so that the pTRD-1 clone differs from the majority of the population of RNA molecules at one site in the $\mathrm{E}_{2}$ glycoprotein gene. Nucleotide number 2370 , in the $6 \mathrm{~K}$ signal peptide, also was found to be a $G$ in both viruses. The $m R N A$ sequences encoding the $6 \mathrm{~K}$ signal proteins of TC-83 and TRD viruses were therefore identical (see Kinney et al., 1986). Nucleotide number 2822 was a $C$ in both viral RNAs so that clone pTC-5, which contains a $U$ at position 2822 , differs from the predominant genomic RNA population at this position. The sequence of the TC-83 RNA (Fig. 1) is shown with a $\mathrm{C}$ at nucleotide position 2822 to reflect the sequence of the TC-83 virus population. This alteration results in Ala at amino acid position $\mathrm{E}_{1}$ 119 instead of the Val encoded by pTC-5. Finally, the question mark in Fig. 2 indicates that the nucleotide difference observed between the pTC-5 and pTRD-1 cDNA clones at position 3366 could not be evaluated by sequencing on RNA templates due to band compression in the sequencing gels. A second, independent TC-83 cDNA clone (pTC-17) was sequenced and found to contain an $A$ at this position, in agreement with clones pTRD-1 and pTRD-7. A G is present 


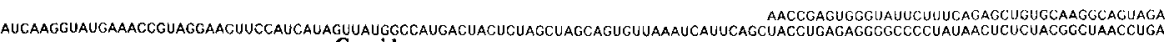

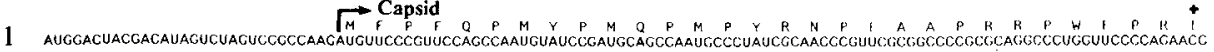

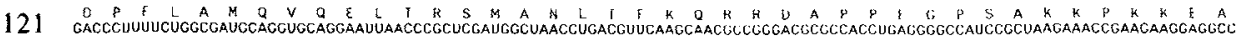

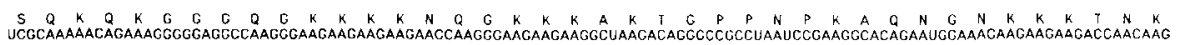

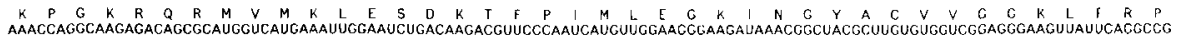
$M$
AUGCAUGUGGAAGGCAAGAUCGACAACGACGUUCUGGCCGCGCUUAAGACGAAGAAAGCAUCCAAAUACGAUCUUGAGUAUGCAGAUGUGCCACAGAACAUGCGGGCGGAUACAUUCAAA

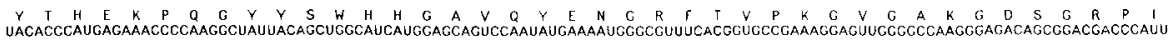

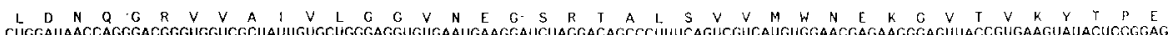
AACUGCGAGCAAUGGUCACUAGUGACCACCAUGUGUCUGCUCGCCAAUGUGACGUUCCCAUGUGCUCAACCACCAAUUUGCUACGACAGAAAACCAGCAGAGACUUIUGGCCAUGCUCAGC

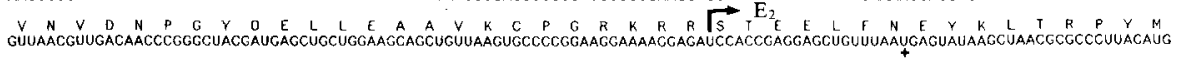

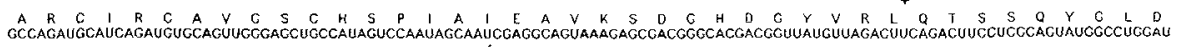

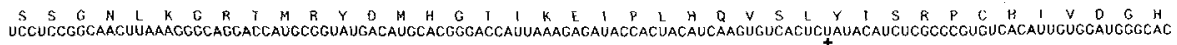

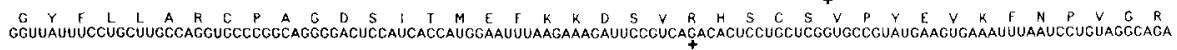

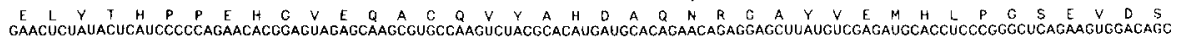

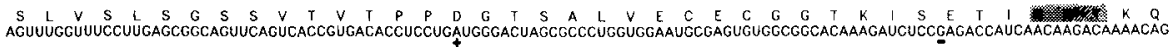

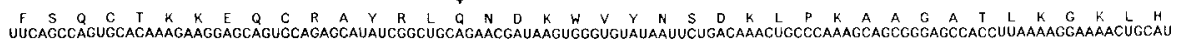
GuCCCAUUCUUGCUGGCAGACGGCAAAUGCAGCGUGCCUCUAGCACCAGAACCUAUGAUAACCUUCGGUUUCAGAUCAGUGUCACUGAAACUGCACCCUAAGAAUCGCACAUAUCUAAUC

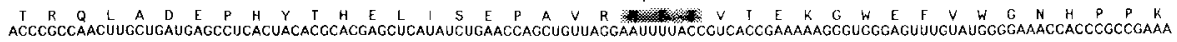

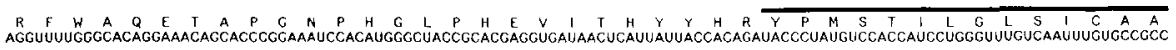

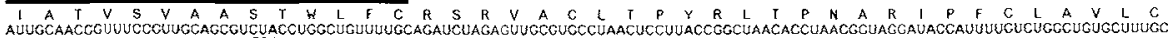
C A R T A R A $\vec{T}_{\mathrm{T}} \mathbf{T} \mathbf{K}$ 作

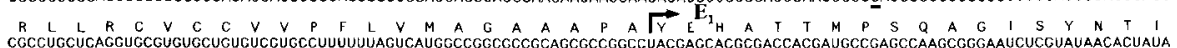
$\underset{\text { GUCAACAGAGCAGGCUACGCACCACUCCCUAUCAGCAUAACACCAACAAAGAUCAAGCUGAUACCUACAGUGAACUUGGAGUACGUCACCUGCCACUACAAAACAGGAAUCGAUUCACCA }}{V}$

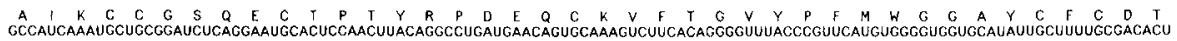

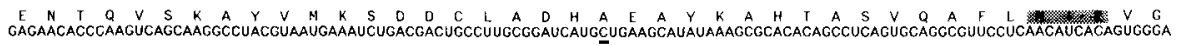
$\underset{\text { GAACACUCUAUUGUGACUACCGUGUAUGUGAAUGGAGAAACUCCUGUGAAUUUCAAUGGGGUCAAAAUAACUGCAGGUCCGCUUUCCACAGCUUGGACACCCUUUGAUCGCAAAAUCGUG }}{\mathrm{E}}$

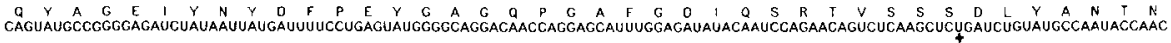
CUAGUGCUGCAGAGACCCAAAGCAGGAGCGAUCCACGUGCCAUACACUCAGGCACCUUCGGGUUUUGAGCAAUGGAAGAAAGAUAAAGCUCGAUCAUUGAAAUUUAGCGCCCCUUUCGGA

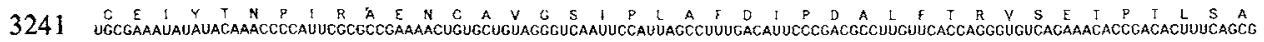

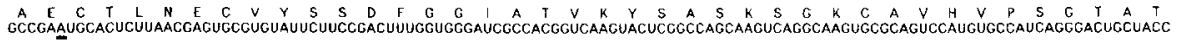

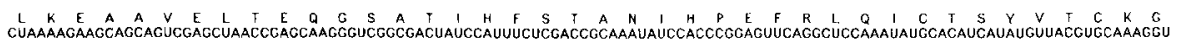

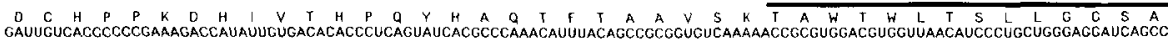

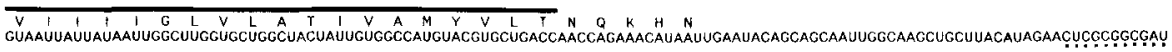

Fig. 1. Nucleotide sequence of the VEE TC-83 26S mRNA and the deduced amino acid sequence of the encoded proteins. The 5'-end of the 26S mRNA (nucleotide position 1) was assigned by its homology with other sequenced alphaviruses (see Kinney et al., 1986, for details; Ou et al., 1982b). An additional 161 nucleotides which are contained in cDNA clone pTC-5 precede the $5^{\prime}$-end of the $26 \mathrm{~S}$ RNA. The sequence complementary to the oligonucleotide used to prime the cDNA synthesis is identified at the 3'end (...) and the terminal nucleotide in clone pTC-5 is identified ( $\uparrow$ ). $3^{\prime}$-Nucleotides not present in clone pTC-5, but previously determined (Ou et al., 1982a), are included after the arrow (underlined nucleotides). Nucleotide differences (13) between cDNA clones pTC-5 and pTRD-1 (Kinney et al., 1986) are underscored ( + or - ). Differences seen at the cDNA level that also were observed between TC-83 and TRD genomic RNA populations are denoted by $(+)$. Differences seen only at the cDNA level are marked by (-). Stippled areas indicate potential Asn-linked glycosylation sites. The single letter amino acid code is used. A, Ala; C, Cys; D, Asp; E, Glu; F, Phe; G, Gly; H, His; I, Ile; K, Lys; L, Leu; M, Met; N, Asn; P, Pro; Q, Gln; R, Arg; S, Ser; T, Thr; V, Val; W, Trp; Y, Tyr. 

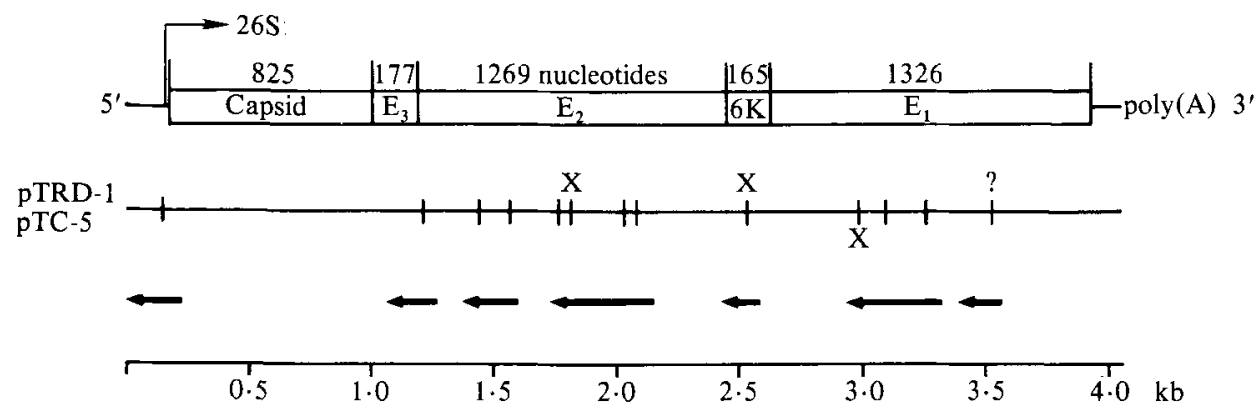

Fig. 2. Regions of TC-83 and TRD genomic RNA sequenced by extension of primers. Vertical lines indicate nucleotide differences between cDNA clones pTC-5 and pTRD-1. cDNA clone differences which were not observed between genomic RNA populations are denoted ' $X$ '. The nucleotide difference which could not be evaluated by RNA sequencing (denoted '?') was resolved by examining an independently derived cDNA clone (see text).

Table 1. Nucleotide and deduced amino acid differences between TRD and TC-83 viruses

\begin{tabular}{|c|c|c|c|c|}
\hline \multirow[b]{2}{*}{ Position } & \multicolumn{2}{|c|}{ Nucleotide } & \multicolumn{2}{|c|}{ Amino acid change } \\
\hline & TRD & TC-83 & TRD & TC- 83 \\
\hline-2 , junction region & A & G & \multicolumn{2}{|c|}{ Non-coding } \\
\hline $1053, E_{2}-7$ & G & $\mathrm{U}$ & Lys & Asn \\
\hline $1285, E_{2}-85$ & $\mathrm{C}$ & $\mathbf{U}$ & His & Tyr \\
\hline $1391, \mathrm{E}_{2}-120$ & $\mathrm{C}$ & G & Thr & Arg \\
\hline $1607, \mathrm{E}_{2}-192$ & U & A & Val & Asp \\
\hline $1866, \mathrm{E}_{2}-278$ & $\mathrm{U}$ & C & \multicolumn{2}{|c|}{ None } \\
\hline $1919, \mathrm{E}_{2}-296$ & $\mathrm{C}$ & U & Thr & Ile \\
\hline 2947, $\mathrm{E}_{1}-161$ & $\mathrm{U}$ & A & Leu & Ile \\
\hline $3099, \mathrm{E}_{1}-211$ & A & U & \multicolumn{2}{|c|}{ None } \\
\hline 3874, $3^{\prime}$-non-coding & UU & $\mathrm{U}$ & \multicolumn{2}{|c|}{ Non-coding } \\
\hline
\end{tabular}

at position 3366 in clone pTC-5. The TC-83 and TRD virus populations therefore probably do not differ at nucleotide 3366; an A was entered at this position in Fig. 1.

A summary of the nucleotide and deduced amino acid differences between TRD and TC-83 viruses is presented in Table 1. Most of the nucleotide differences (six) are clustered in the $\mathrm{E}_{2}$ glycoprotein gene. Of these six differences, five resulted in non-conservative amino acid changes in the $E_{2}$ protein. The charge of the $E_{2}$ protein is altered as a result of three of these changes at nucleotide positions 1053,1391 and 1607 . These three alterations make the $E_{2}$ of $T C$ 83 vaccine virus slightly less basic than that of its virulent parent. Neither of the nucleotide differences between the $E_{1}$ genes resulted in an alteration in the chemical character of the $E_{1}$ proteins. One of the $E_{1}$ mutations is silent and the other resulted in the substitution of an Ile for Leu.

The $26 \mathrm{~S}$ junction region, that portion of the genomic RNA containing the 3 -end of the nonstructural protein genes and the $5^{\prime}$-start of the structural protein genes, contains a highly conserved nucleotide sequence in other alphaviruses (Ou et al., 1982b). Both TC-83 and TRD viruses deviated from this pattern (Fig. 3). An ochre (UAA) termination codon occurs eight nucleotides before the 26S RNA start site, which slightly shortens the carboxyl terminus of nsP4. This terminator may be a general distinguishing feature of VEE viruses because we have also found it in the junction regions of two enzootic ID strains from Colombia (our unpublished results). Two nucleotides preceding the 26S RNA $5^{\prime}$-end is a confirmed difference between TC83 and TRD genomic RNAs (Fig. 3). This A to G transition (Fig. 3) may alter the hypothetical viral replicase recognition site. 


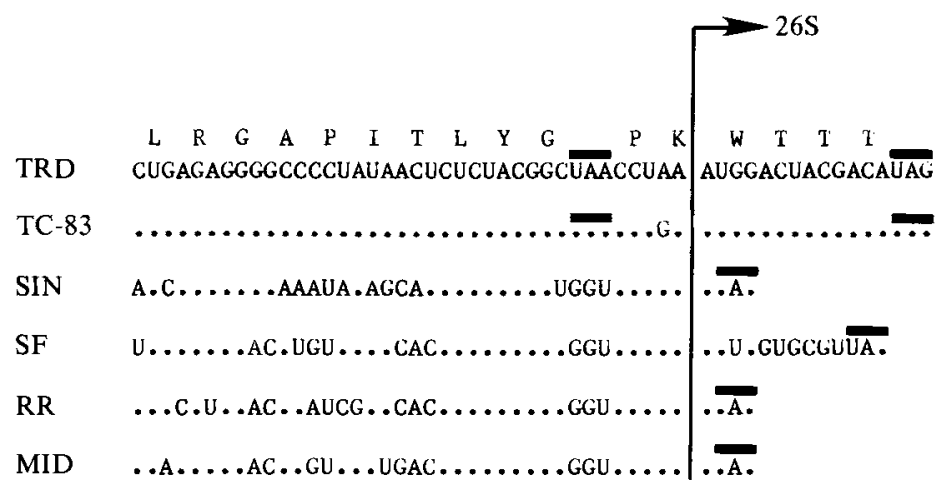

Fig. 3. Comparison of alphavirus sequence in the region containing the start of the 26S RNA. Data for Sindbis (SIN), Semliki Forest (SF), Ross River (RR) and Middelburg (MID) viruses were obtained from Ou et al. (1982b). The amino acid sequence shown is the carboxyl terminus of non-structural protein 4 (nsP4). Dots indicate nucleotide identity with the VEE TRD sequences. Solid bars mark termination codons.

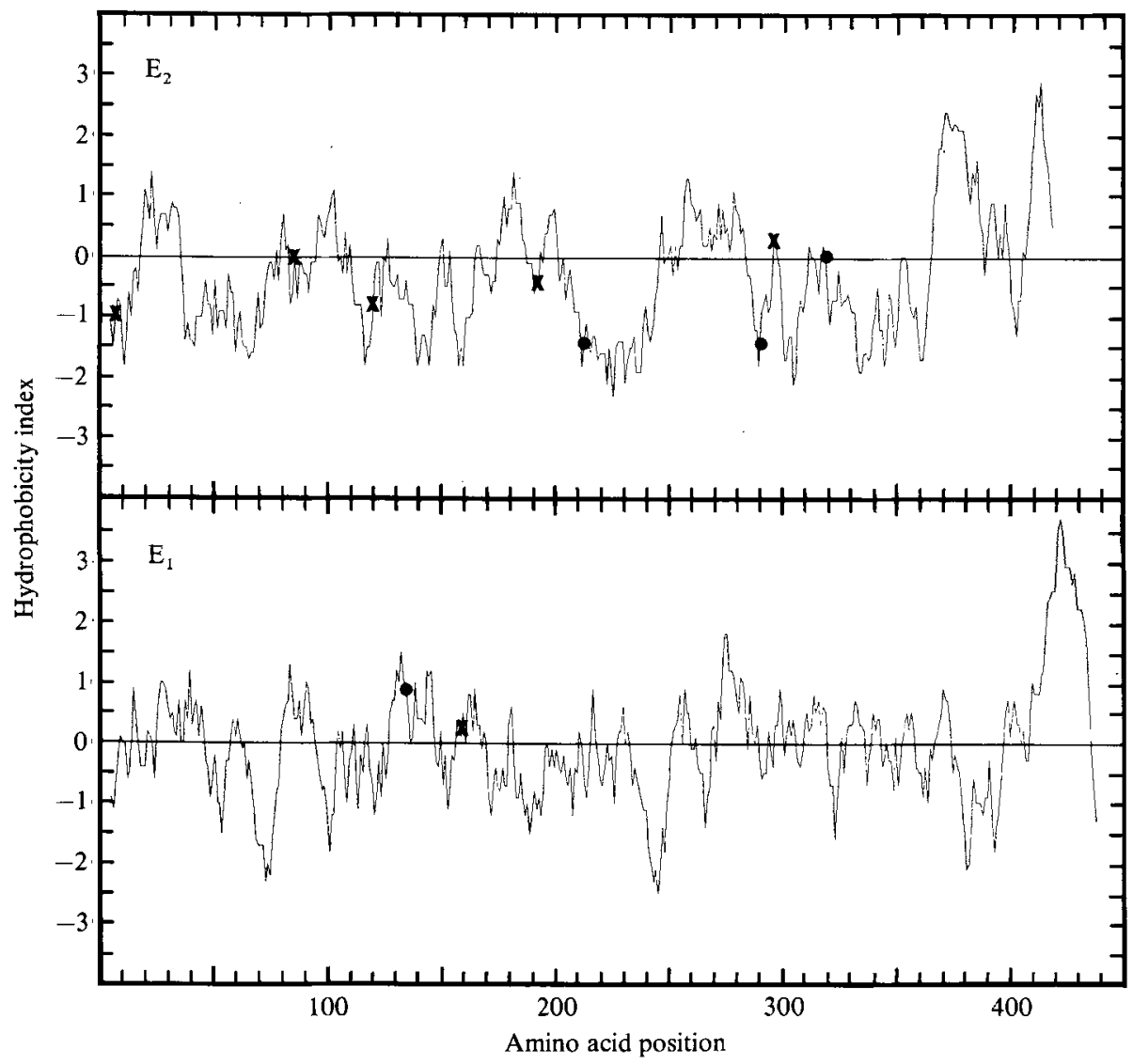

Fig. 4. Hydrophobicity profiles of the TC-83 virus glycoproteins. The average hydrophobicity of every nine amino acid-long segment of the $E_{2}$ and $E_{1}$ proteins was computed using the indices of Kyte \& Doolittle (1982). The positions of amino acid differences between TC-83 and TRD viruses are marked by ' $\mathrm{X}$ '. Potential Asn-linked glycosylation sites are shown ( $\mathbf{O})$. 
For completeness, the one other known nucleotide difference between TC-83 and TRD viruses is presented in Table 1. One uridine is deleted from TC-83 virus (Ou et al., 1982a) at nucleotide 3874. This deletion makes the 3'-non-coding region 120 nucleotides long, compared with 121 nucleotides in TRD virus. The deleted uridine does not fall within the highly conserved string of 19 nucleotides immediately adjacent to the poly(A) tract, which has been postulated to serve as a replicase recognition signal (Ou et al., 1982 a).

The six deduced amino acid differences between TRD and TC-83 viruses are positioned on hydrophobicity plots of the TC-83 $E_{2}$ and $E_{1}$ proteins (Fig. 4). The amino acid differences, marked ' $X$ ', are predominantly in hydrophilic domains of $E_{2}$. One change (amino acid position $\left.E_{2}-296\right)$ affects a hydrophobic region of $E_{2}$. The one amino acid change in $E_{1}$, a conservative Leu to Ile substitution, occurs in a hydrophobic region. Closed circles in Fig. 4 indicate potential $N$-glycosylation sites, Asn-X-Ser or Asn-X-Thr sequences (where $\mathrm{X}$ is any amino acid), which are a necessary but not sufficient condition for glycosylation. None of the three potential glycosylation sites in $E_{2}$, nor the single site in $E_{1}$, was directly altered by the observed nucleotide changes which occurred during attenuation of TRD virus.

\section{DISCUSSION}

RNA viral genomes are so highly mutable that the nucleotide sequence of virus propagated from a clone may not be singular. The sequence of an RNA virus population is probabilistic whenever the number of bases in the genome exceeds the reciprocal of the base misincorporation frequency per genome doubling (Holland, 1984). Base-substitution frequencies for vesicular stomatitis at one site in a highly conserved region of the genome average between $10^{-4}$ and $4 \times 10^{-4}$ per base incorporated at that site (Steinhauer \& Holland, 1986). A similar base-misincorporation frequency (between $10^{-3}$ and $10^{-4}$ ) has been calculated for RNA phage $\mathrm{Q} \beta$ (Domingo et al., 1978). Therefore, progeny of a VEE virus, which has a $12 \mathrm{~kb}$ genome, will probably differ both from their parent and from each other by at least one nucleotide.

The nucleotide sequence of cDNA encoding the structural protein region of the benign TC-83 virus was determined in order to compare it with a similar clone derived from the virulent TRD strain (Kinney et al., 1986). Sequencing of cDNA rather than genomic RNA was performed because of the greater confidence which results from sequencing both strands of a cDNA and because we intend to use these cDNAs to express their encoded viral proteins. Thirteen nucleotide differences were found between the two VEE cDNA clones. Four of these differences were shown to result from reverse transcriptase errors or the cloning of a minor variant from the 42S RNA population. The nine remaining nucleotide differences were evaluated as potential determinants of VEE virus neurovirulence.

The nine mutations in TC-83 virus are not randomly distributed over the structural gene region. They are clustered in the gene for the $\mathrm{E}_{2}$ glycoprotein. All five of the non-conservative amino acid changes deduced from the nucleic acid sequences are located in $E_{2}$. Although two mutations occurred in the $E_{1}$ glycoprotein gene, one was silent and one resulted in a conservative Leu to Ile change in the amino acid incorporated. No mutations were found in the capsid nor in the $\mathrm{E}_{3}$ or $6 \mathrm{~K}$ signal sequences, which together comprise $32 \%$ of the structural protein genes. The absence of mutations in the signal sequences probably is not remarkable in view of their short lengths.

Three mutations in $E_{2}$ alter the charge of hydrophilic domains, which are likely to be on the surface of the virus and accessible to the immune system of the host. All five amino acid substitutions in $E_{2}$ are potentially capable of altering its surface topography and, thereby, its surface-mediated functions. Both the ability to elicit virus type-specific neutralizing antibody and haemagglutination have been associated with the $\mathrm{E}_{2}$ of VEE virus (Pederson \& Eddy, 1974; France et al., 1979; Kinney et al., 1983). The antigenic makeup of VEE $\mathrm{E}_{2}$ glycoproteins has been explored in detail with monoclonal antibodies (Roehrig et al., 1982; Roehrig \& Mathews, 1985). Four monoclonal antibodies demonstrate differential reactivity with the $E_{2}$ of TC-83 and TRD viruses; two have neutralization and haemagglutination-inhibition activity with TRD virus but only neutralization activity with TC-83 virus.

One mutation was located in the non-coding junction region, two nucleotides before the 5 '-end 
of the $26 \mathrm{~S}$ mRNA. This A-to-G transition may possibly affect the postulated viral replicase recognition site. Replication of TC-83 virus has been compared with its virulent parent in vitro (Mecham \& Trent, 1983). TC-83 and TRD viruses have similarly shaped growth curves in Vero cells, but 2.5 times less TC-83 virus is produced early in the replication cycle concomitant with a depressed production of $26 \mathrm{~S} \mathrm{mRNA}$. The relationship of this finding to virulence is unknown. There is precedent, however, for a single nucleotide change in a non-coding region to alter neurovirulence substantially in the Sabin type 3 poliovaccine genome (Evans et al., 1985).

Although the two translationally silent mutations (one each in $E_{2}$ and $E_{1}$ ) do not, of course, perturb the structure of the glycoprotein spike, they may not be irrelevant to the modification of neurovirulence. RNAs may replicate more slowly if they have translationally silent changes, as was suggested by the $Q \beta$ studies of Domingo et al. (1978). The competitive disadvantage of a $Q \beta$ variant containing a silent mutation could not be specifically associated with the silent nucleotide substitution, however, since other mutations may have been concurrently present in the genome in unanalysed regions.

TRD and TC-83 viruses do not differ in the number or position of potential $N$-glycosylation sites in their surface proteins. Three Asn- $X-T h r$ sequences occur in $E_{2}$ and one in $E_{1}$. One is also present in $\mathrm{E}_{3}$. $\mathrm{E}_{3}$ forms part of the glycoprotein spike of Semliki Forest virus, but it is not detectable in VEE virions (Simons et al., 1980). We believe that the $\mathrm{E}_{2}$ glycoproteins of both TC83 and TRD viruses are glycosylated at all three Asn-X-Thr sites. Mecham \& Trent (1982b) suggested that TRD and TC-83 viruses differ in the extent of glycosylation of their $E_{2}$ proteins because the TRD $E_{2}$ had three glycosylated tryptic peptide peaks resolvable by reverse-phase high-pressure liquid chromatography, whereas TC-83 $\mathrm{E}_{2}$ had only two. The deduced amino acid sequence of the TC- $83 \mathrm{E}_{2}$ reveals that its second glycosylation site occurs in a tryptic peptide fragment whose composition (NPTYLITR) differs from the cognate tryptic fragment of TRD virus (NPTYLTTR). The substitution of Ile for $\mathrm{Thr}$ in this peptide alters the total hydrophobicity index (calculated from the amino acid values suggested by Kyte \& Doolittle, 1982) from -9.2 (TRD) to -4.0 (TC-83). The increased hydrophobicity of the TC-83 glycopeptide probably decreases its mobility in reverse-phase chromatography. In the work of Mecham \& Trent (1982b), the first (most hydrophilic) of the three glycosylated tryptic peptide peaks of TRD $E_{2}$ is missing in the TC-83 $E_{2}$ chromatogram, and the second TC-83 peak is larger in area than the second TRD peak by an amount equal to that of the first TRD peak. This profile indicates that the Thr to Ile change shifted the first glycopeptide peak seen in TRD $E_{2}$ into the more hydrophobic second peak, and that the TRD and TC-83 $\mathrm{E}_{2}$ proteins are equally glycosylated. No differences were seen between the tryptic glycopeptide chromatograms of the $\mathrm{E}_{1}$ proteins, although more than one glycopeptide was resolved, perhaps because of incomplete trypsin digestion of the $E_{1}$. The difference in neurovirulence of the two viruses, therefore, cannot be associated with differences in the extent of glycosylation of their surface proteins.

The five amino acid substitutions seen in the TC- 83 virus $\mathrm{E}_{2}$ glycoprotein, as well as the single nucleotide substitution in the non-coding junction, are candidates for the molecular determinants of VEE neurovirulence. We are evaluating the relative significance of these putative determinants by sequencing the $E_{2}$ and junction regions of phenotypic revertants of TC-83 vaccine virus. TC-83-derived viruses that kill hamsters and mice have been isolated from the throats of several human vaccinees and from hamsters directly after a single passage of the vaccine (Jahrling \& Scherer, 1973b; P. B. Jahrling, personal communication). Vaccine production lots that are neurovirulent for mice and hamsters (E. R. Aycardi, personal communication) will also be examined.

This study augments the growing body of data implicating surface protein structure in the modulation of alphavirus virulence. Neuroadaptation of the Sindbis alphavirus was accompanied by alterations in $E_{1}$ and $E_{2}$ conformation detected by monoclonal antibodies. Most of the changes detected were clustered on $\mathrm{E}_{2}$ (Stanley et al., 1985). Sequence analysis of the Sindbis virus $E_{2}$ glycoprotein genes of several closely related attenuated, virulent and virulentrevertant strains has revealed two sites which affect neurovirulence in newborn mice $(N$. $L$. Davis, F. J. Fuller \& R. E. Johnston, personal communication). A temperature-sensitive, attenuated mutant of VEE virus exhibited a lower isoelectric point of its $E_{1}$ glycoprotein. Reversion of this mutation correlated the $\mathrm{E}_{1}$ alteration with attenuation (Emini \& Wiebe, 1981). 
The surface proteins of several viruses have been identified as determinants of pathogenicity. A single amino acid substitution in the rabies glycoprotein prevents rabies viruses from producing lethal infection in adult mice (Dietzschold et al., 1983). Although neurovirulence is a polygenic character in influenza viruses, the cleavage of the haemagglutinin plays a critical role (Bosch et al., 1981; Kawaoka et al., 1984). Reassortant studies of the California group viruses (Bunyaviridae) correlated murine virulence with the M RNA segment. This segment encodes the glycoproteins which mediate virus attachment and perhaps tissue tropism (Shope et al., 1981; Tignor et al., 1983). Neurotropism of mammalian reoviruses is determined by the outer capsid proteins $\mu 1 \mathrm{C}$ and the haemagglutinin $1 \sigma$ (Fields \& Greene, 1982).

This investigation was confined to the 3 'terminal one-third of the TC-83 and TRD viral genomes. It is in this structural protein region that all of the observable differences in the $T_{1}$ ribonuclease-resistant oligonucleotides are located (Mecham \& Trent, 1982a). Since oligonucleotide fingerprinting resolves fragments comprising about $10 \%$ of the genome (Domingo et al., 1978), the actual number of mutations in a virus probably exceeds the number of oligonucleotide spot changes observed. The nine nucleotide differences in TC-83 virus $26 \mathrm{~S}$ mRNA were reflected in the disappearance of three oligonucleotide spots (Mecham \& Trent, 1982a); thus, in this instance, the ratio of actual mutations to fingerprint differences is three. As a consequence, there may be mutations in the genes which encode the non-structural proteins of TC-83 virus which contribute to its avirulent phenotype.

We thank Vickie Brown for technical assistance with portions of this work and Susan Ure for typing the manuscript.

\section{REFERENCES}

BAKER, E. F., JR, SASSO, D. R., MANESS, K., PRICHARD, W. D. \& PARKER, R. L. (1978). Venezuelan equine encephalomyelitis vaccine (strain TC-83) : a field study. American Journal of Veterinary Research 39, $1627-$ 1631.

BEAUCAGE, S. L. \& CARUTHERS, M. H. (1981). Deoxynucleotide phosphoramidites - a new class of key intermediates for deoxypolynucleotide synthesis. Tetrahedron Letters 22, 1859-1862.

BERGE, T. O., BANKS, I. S. \& TIGERTT, w. D. (1961). Attenuation of Venezuelan equine encephalomyelitis virus by in vitro cultivation in guinea-pig heart cells. American Journal of Hygiene 73, 209-218.

BOSCH, F. X., GARTEN, W., KLENK, H. D. \& ROTT, R. (1981). Proteolytic cleavage of influenza virus hemagglutinins: primary structure of the connecting peptide between HA1 and HA2 determines proteolytic cleavability and pathogenicity of avian influenza viruses. Virology 113, 725-735.

BURKE, D. S., RAMSBURG, H. H. \& EDELMAN, R. (1977). Persistence in humans of antibody to subtypes of Venezuelan equine encephalomyelitis (VEE) virus after immunization with attenuated (TC-83) VEE virus vaccine. Journal of Infectious Diseases 136, 354-359.

CALISHER, C. H. \& MANESS, K. S. C. (1975). Laboratory studies of Venezuelan equine encephalitis virus in equines, Texas, 1971. Journal of Clinical Microbiology 2, 198-205.

DIETZSCHOLD, B., WUNNER, W. H., WIKTOR, T. J., LOPES, A. D., LAFON, M., SMITH, C. L. \& KOPROWSKI, H. (1983). Characterization of an antigenic determinant of the glycoprotein that correlates with pathogenicity of rabies virus. Proceedings of the National Academy of Sciences, U.S.A. 80, 70-74.

DOMINGO, E., SABO, D., TANIGUCHI, T. \& WEISSMAN, C. (1978). Nucleotide sequence heterogeneity of an RNA phage population. Cell 13, 735-744.

EDDY, G. A., MARTIN, D. H., REEVES, w. C. \& JOHNSON, K. M. (1972). Field studies of an attenuated Venezuelan equine encephalomyelitis vaccine (strain TC-83). Infection and Immunity 5, 160-163.

EMINI, E. A. \& WIEBE, M. E. (1981). An attenuated mutant of Venezuelan encephalitis virus: biochemical alterations and their genetic association with attenuation. Virology 110, 185-196.

EVANS, D. M. A., DUNN, G., MINOR, P. D., SCHILD, G. C., CANN, A. J., STANWAY, G., ALMOND, J. W., CURREY, K. \& MAIZEL, J. V., JR (1985). Increased neurovirulence associated with a single nucleotide change in a noncoding region of the Sabin type 3 poliovaccine genome. Nature, London, 314, 548-550.

FIELDS, B. N. \& GREENE, M. I. (1982). Genetic and molecular mechanisms of viral pathogenesis: implications for prevention and treatment. Nature, London 300, 19-23.

FILLIS, C. A. \& CALISHER, C. H. (1979). Neutralizing antibody response of humans and mice to vaccination with Venezuelan encephalitis (TC-83) virus. Journal of Clinical Microbiology 10, 544-549.

FRANCE, J. K., WYRICK, B. C. \& TRENT, D. W. (1979). Biochemical and antigenic comparisons of the envelope glycoproteins of Venezuelan equine encephalomyelitis virus strains. Journal of General Virology 44, 725-740.

GROOT, H. (1972). The health and economic impact of Venezuelan equine encephalitis (VEE). In Venezuelan Encephalitis, pp. 7-16. Sci. Pub. No. 243. Washington, D.C.: Pan American Health Organization.

HOLLAND, J. J. (1984). Continuum of change in RNA virus genomes. In Concepts in Viral Pathogenesis, pp. 137-143. Edited by A. L. Notkins \& M. B. A. Oldstone. New York: Springer-Verlag.

JAHRLING, P. B. \& SCHERER, W. F. (1973a). Histopathology and distribution of viral antigens in hamsters infected with virulent and benign Venezuelan encephalitis viruses. American Journal of Pathology 72, 25-34. 
JAHRLING, P. B. \& SCHERER, W. F. (1973b). Homogeneity of Venezuelan encephalitis virion populations of hamstervirulent and benign strains, including the attenuated TC 83 vaccine. Infection and Immunity 7, 905-910.

JAHRLING, P. B. \& SCHERER, W. F. $(1973 c)$. Growth curves and clearance rates of virulent and benign Venezuelan encephalitis viruses in hamsters. Infection and Immunity 8, 456-462.

KAWAOKA, Y., NAEVE, C. W. \& WEBSTER, R. G. (1984). Is virulence of N5N2 influenza viruses in chickens associated with loss of carbohydrate from the hemagglutinin? Virology 139, 303-316.

KINNEY, R. M., TRENT, D. W. \& FRANCE, J. K. (1983). Comparative immunological and biochemical analyses of viruses in the Venezuelan equine encephalitis complex. Journal of General Virology 64, $135-147$.

KINNEY, R. M., JOHNSON, B. J. B., BROWN, V. L. \& TRENT, D. W. (1986). Nucleotide sequence of the 26S mRNA of the virulent Trinidad donkey strain of Venezuelan equine encephalitis virus and deduced sequence of the encoded structural proteins. Virology (in press).

KYTE, J. \& DOOLITTLE, R. F. (1982). A single method for displaying the hydropathic character of a protein. Journal of Molecular Biology 157, 105-132.

LE BLANC, P. A., SCHERER, W. F. \& SUSSDORF, D. H. (1978). Infections of congenitally athymic (nude) and normal mice with avirulent and virulent strains of Venezuelan encephalitis virus. Infection and Immunity. 21, 779-785.

MCKINNEY, R. W., BERGE, T. O., SAWYER, W. D., TIGERTT, W. D. \& CROZIER, D. (1963). Use of an attenuated strain of Venezuelan equine encephalomyelitis virus for immunization in man. American Journal of Tropical Medicine and Hygiene 12, 597-603.

MECHAM, J. O. \& TRENT, D. W. (1982a). A comparison of the $26 \mathrm{~S}$ mRNAs and structural proteins of an equine virulent Venezuelan encephalitis virus and its vaccine derivative. Virology 121, 251-261.

MECHAM, J. O. \& TRENT, D. W. (1982b). Glycosylation patterns of the envelope glycoproteins of an equine-virulent Venezuelan equine encephalitis virus and its vaccine derivative. Journal of General Virology 63, $121-129$.

MECHAM, J. O. \& TRENT, D. W. (1983). A biochemical comparison of the in vitro replication of a virulent and an avirulent strain of Venezuelan encephalitis virus. Journal of General Virology 64, 1111-1119.

OU, J.-H., STRAUSS, E. \& STRAUSS, J. H. (1981). Comparative studies of the 3 '-terminal sequences of several alphavirus RNAs. Virology 109, 281-289.

OU, J.-H., TRENT, D. W. \& STRAUSS, J. H. (1982a). The 3'-non-coding regions of alphavirus RNAs contain repeating sequences. Journal of Molecular Biology 156, 719-730.

OU, J.-H., RICE, C. M., DALGARNo, L. STRAUSS, E. G. \& STRAUSS, J. H. (1982b). Sequence studies of several alphavirus genomic RNAs in the region containing the start of the subgenomic RNA. Proceedings of the National Academy of Sciences, U.S.A. 79, 5235-5239.

PEDERSON, C. E. \& EDDY, E. A. (1974). Separation, isolation, and immunochemical studies of the structural proteins of Venezuelan equine encephalomyelitis virus. Journal of Virology 14, 740-744.

ROEHRIG, J. T. \& MATHEWS, J. H. (1985). The neutralization site on the $\mathrm{E}_{2}$ glycoprotein of Venezuelan equine encephalomyelitis (TC-83) virus is composed of multiple conformationally stable epitopes. Virology 142, 347356.

ROEHRIG, J. T., DAY, J. W. \& KINNEY, R. M. (1982). Antigenic analysis of the surface glycoproteins of a Venezuelan equine encephalomyelitis virus (TC-83) using monoclonal antibodies. Virology 118, 269-278.

SANGER, F. COULSON, A. R. (1978). The use of thin acrylamide gels for DNA sequencing. FEBS Letters 87, 107110.

SANGER, F., NICKLEN, S. \& COULSON, A. R. (1977). DNA sequencing with chain-terminating inhibitors. Proceedings of the National Academy of Sciences, U.S.A. 74, 5463-5467.

SHOPE, R. E., ROZHON, E. J. \& BISHOP, D. H. L. (1981). Role of the middle-sized bunyavirus RNA segment in mouse virulence. Virology 114, 273-276.

SIMONS, K., GAROFF, H. \& HelENIUS, A. (1980). Alphavirus proteins. In The Togaviruses, pp. 317-333. Edited by R. W. Schlesinger. New York: Academic Press.

STANLEY, J., COOPER, S. J. \& GRIFFIN, D. E. (1985). Alphavirus neurovirulence: monoclonal antibodies discriminating wild-type from neuroadapted Sindbis virus. Journal of Virology 56, 110-119.

STEINHAUER, D. A. \& HOLLAND, J. J. (1986). Direct method for quantitation of extreme polymerase error frequencies at selected single base sites in viral RNA. Journal of Virology 57, 219-228.

STRAUSS, E. G. \& STRAUSS, J. H. (1986). Structure and replication of the alphavirus genome. In The Togaviruses and Flaviviruses, pp. 35-90. Edited by S. Schlesinger \& M. Schlesinger. New York: Plenum Press.

TIGNOR, G. H., BURRAGE, T. C., SMITH, A. L., SHOPE, R. E. \& BISHOP, D. H. L. (1983). California serogroup gene structure-function relationships: virulence and tissue tropisms. In California Serogroup Viruses, pp. 129-138. Edited by C. H. Calisher \& W. H. Thompson. New York: Alan R. Liss.

TRENT, D. W., ClEWLeY, J. P., FRANCE, J. K. \& BISHOP, D. H. L. (1979). Immunochemical and oligonucleotide fingerprint analyses of Venezuelan equine encephalomyelitis complex viruses. Journal of General Virology 43 , $365-381$.

WALTON, T. E. \& JOHNSON, K. M. (1972). Persistence of neutralizing antibody in equidae vaccinated with Venezuelan equine encephalomyelitis vaccine strain TC-83. Journal of the American Veterinary Medical Association 161, 916-918.

WALTON, T. E., BRANTIGAM, F. E., FERRER, J. A. \& JOHNSON, K. M. (1972). Epizootic Venezuelan equine encephalomyelitis in Central America. Disease pattern and vaccine evaluation in Nicaragua, $1969-1970$. American Journal of Epidemiology 95, 247-254. 